\title{
Remote controlled braking actuation for motorcycle safety system development
}

\author{
Cosimo Lucci, Lorenzo Berzi, Niccolò Baldanzini \\ Dept. of Industrial Engineering - DIEF \\ Florence, Italy \\ Lorenzo.berzi@unifi.it
}

\author{
Giovanni Savino \\ Dept. of Industrial Engineering - DIEF \\ Florence, Italy \\ Monash University Accident Research Centre, \\ Melbourne, Australia
}

\begin{abstract}
Amongst various initiatives in the last 20 years for the improvement of the safety of any road vehicles, Autonomous emergency braking for Motorcycles (MAEB) could provide a significant reduction in the number of crashes or the mitigation of crash injury outcomes. User acceptance of this system, however, is still subjected to a number of uncertainties due to the peculiar needs of two-wheel riding. The activity proposed in this paper is inspired by the need to build a laboratory motorcycle to be used in teaching, research and learning activities. A braking device to be used for testing of remote-activated braking events in real-world conditions is presented. The device was conceived in order to be low-cost, removable and not invasive in the vehicle, since it would act on existing levers. A simple control system based on commercial components is introduced; the device targeted a deceleration of $5 \mathrm{~m} / \mathrm{s}^{2}$ (expected to be a safe value for most riding conditions); the system would be tested within notprofessional riders. Our results include a brief characterization of existing braking system, a description of calibration method and the discussion of data obtained during real-world testing.
\end{abstract}

Keywords-Motorcycle; Autonomous braking; Riders safety; Active safety; Vehicle integration.

\section{INTRODUCTION}

The ambitious goals targeted by the European Commission, aiming at cutting the road toll by 50\% in the period 2020-30, require that effective countermeasures are identified and implemented for all modes of transport, including vulnerable road users such as powered two wheelers (PTWs). According to previous research, autonomous emergency braking (AEB) is one active system that may contribute to a mitigation of PTW crashes. Two main research topics can be identified in literature. The first one investigates the potential benefit for two wheeler riders (motorbikes, bicycles) due to the adoption of AEB or other active systems by four wheel vehicles (the less vulnerable counterpart in the circulating fleet, see [1][2]). The second one is focused on adoption of active safety systems directly on two-wheel vehicles. In case of autonomous braking needs, the system is usually designed to detect imminent collision situations and deploy an automatic braking event even without the input of the rider. Retrospective studies showed that autonomous emergency braking applied to PTWs (also known as motorcycle AEB, or MAEB), may influence about one third of all PTW crashes in traffic contexts such as Italy, Sweden and Australia [3][4]. An encouraging fact on this technology is that AEB is currently fully operative and already on the market for passenger cars and other vehicles [5], [6]. Much more than for AEB, one critical issue to the introduction of MAEB on series vehicles is related to the acceptance of the system by end-users. In the last ten years, both lab [7] and field tests were conducted to determine the appropriate working conditions of MAEB. Field tests involving participants focused on expert riders [8][9], or low unexpected decelerations in straight line [10]. Recently, test were conducted also with higher deceleration [11]. However, the feasibility of automatic braking and in general of advanced safety systems [12] on single track vehicles has not been thoroughly confirmed yet, and it is therefore necessary that before introducing such a system on the PTW market, further feasibility tests involving participants should be conducted. The following activities are essential: (i) assess if normal riders would easily manage unexpected decelerations; (ii) identify the limits of intervention in terms of deceleration and jerk; and (iii) identify the possible scenarios of intervention. To complete these tasks, new field tests are required and a test vehicle able to perform remotecontrolled deceleration and data acquisition has to be developed.

\section{REMOTE BRAKING SYSTEM: GOALS AND ACTIVITIES}

\section{A. Scope of the activity}

In this paper, we present the development and initial testing of an automatic braking device that can be easily installed on test PTWs to conduct early stage experiments in the field for the investigation of the feasibility and acceptance of automatic decelerations on motorcycles. The automatic braking device should brake a motorcycle without the intervention of the ride via remote control activation.

Since autonomous emergency braking has the purpose of mitigating inevitable impacts, the related braking device must fulfil strict constraints in terms of braking actuation and performances. Moreover, since the device will be employed in 
field tests with common riders, it must guarantee high safety standards.

The braking device is designed to work in urban scenarios, with speeds up to $50 \mathrm{~km} / \mathrm{h}$. This means that it must be able to perform braking force not only in a straight line but also during lateral manoeuvres and curve. To investigate the feasibility of automatic decelerations, it is necessary to achieve decelerations greater than those tested so far [8] [10] [11]. For this reason, the braking device must apply enough braking force so that the motorcycle reaches decelerations up to $6 \mathrm{~m} / \mathrm{s}^{2}$. To reach a deceleration of $6 \mathrm{~m} / \mathrm{s}^{2}$ without the availability of a combined braking systems, it is necessary to brake the front wheel. For this reason, the braking device presented in this paper was applied to the front brake only. Given the fact that the device will be employed in pilot tests to evaluate the acceptability of automatic decelerations on motorcycles, it is essential that the braking device has a wide capability to be adjusted in terms of resulting deceleration and jerk. The device will be used to identify suitable working parameters for MAEB application. In addition, the device must be removable, and it must not modify permanently the motorcycle. To ensure the safety of the rider during the tests, the braking device must be easily disengaged by the rider also during an automatic braking event.

Such braking device will enable performing pilot tests to identify suitable working parameters for MAEB, and to define a test protocol for the analsysis of rider acceptance to unexpected deceleration events through field testing involving participants.

\section{B. Instrumented vehicle characteristics}

The test vehicle where the device is installed is a Ducati Monster 821 MY2018, a conventional street style motorcycle equipped with an $821 \mathrm{cc}$ double cylinder engine. The test vehicle is equipped with a special safety outriggers device to prevent any fall or impact of the vehicle with the ground. The effectiveness of these safety outriggers is guaranteed by extensive testing with motorcyclists carried out before application in this project: they are designed to intervene at adjustable roll angles and work smoothly to minimize the risk of the driver falling because of the intervention.

The instrumentation installed on the vehicle includes a GoPro camera mounted on the left outrigger, facing the motorcycle. It provides a lateral view of the motorcycle including the braking device and the rider.

A data logger is installed (Race Technology DL1 Club) performing data collection at a sample rate of $100 \mathrm{~Hz}$. It provides vehicle speed, gear number, engine RPM, clutch usage, front and rear brake activation, front brake pressure, and throttle. The data are logged directly from the motorcycle's CAN Bus. The data logger provides also data from internal sensors: measures of longitudinal and lateral accelerations, roll rate and position with $20 \mathrm{~Hz}$ Global Positioning System (GPS). To record the device operation condition, custom analog signals are also logged.

\section{Implementation of the system: mechanical devices}

The braking device that we present was designed with the purpose to be simple and easily adjustable to different testing conditions, safe for the rider in every circumstances and based on standard components, to guarantee high affordability and fast assembly. The device actuated automatic braking by acting directly on the front brake lever via electromechanical system, without direct intervention on the hydraulic brake circuit. This device allows the rider to use the front brake during the tests. The braking device is external, easily removable from the motorcycle so that the vehicle can be completely reconfigured as original. Once the braking device is removed, the motorcycle returns as original and no intervention is required to restore the standard brakes. The braking device is designed to give to the rider the chance to disengage mechanically the actuator in every condition.

The braking device was installed on the motorbike using a frame attached to the right fork. The main $\mathrm{T}$ crossbeam placed under the brake lever composes this frame; there are also two brackets for additional structure stiffness and resistance. The motor and the transmission are housed in the upper part of the frame; the support brackets and the connection to the fork are linked in the lower part of the frame. The structure of the frame enables several possible configurations for setting up the device on the fork and adjusting its position compared to the handlebar and brake pump. This makes the device adaptable to other motorcycles and flexible to different layouts. A $12 \mathrm{~V}$ epicyclic gearbox motor characterized by a reduction ratio of 100:1 actuates the braking device. The gearbox motor is installed on the frame of the braking device through two brackets.

The transmission of the power from the electric motor to the brake lever is made up of several standard components. A joint, provided with elastic pins, connected the crankshaft to the driven shaft and the brake actuator. A ball bearing was added to support the crankshaft and the joint. A shaft connecting the crankshaft joint and a knuckle joint, a knuckle joint that allows the rotation of the second part of the actuator, and a spherical joint, composed the brake actuator. The spherical joint was then linked to the brake lever through a pivot, which allows the mechanical disengagement of the actuator.

Due to the inclination between the rotation axis of the actuator and the brake lever, during the rotation of the brake lever the point of contact executes a trajectory that cannot be covered by a rigid mechanism. For this reason, the connection between the brake lever and the actuator was obtained using a spherical joint, which is free to slide alongside the brake lever. The kinematic mechanism is therefore able to rotate the brake lever following its trajectory. To reduce stress on the brake cylinder the original brake lever was replaced with one using a spherical joint.

To ensure that the movement of the actuator is limited in a safe range, a limit switch made of an aluminum block was introduced, made integral with the driven shaft through elastic pins. Two screws settled on the frame limited the rotation of the block. Tuning the position of the screws produced the tuning of the desired range of movement of the brake lever. A 
tunable tension spring was also installed to ensure that the brake lever returned in the initial position after any automatic braking event. The full system is shown in Fig. 1.

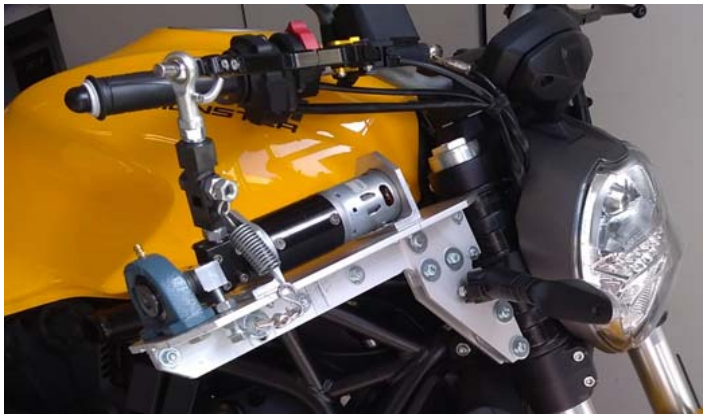

Fig. 1. Mechanical braking system installed on the motorcycle.

\section{Implementation of the system: control and electronic devices}

After the definition of the specifications of the mechanical brake actuator, the characteristics of its electric drive and control system were defined accordingly. The required features were the following: (i) modulation and control of target vehicle deceleration through electric motor current control; (ii) communication enabling remote control input; (iii) ability to actuate the motor-epicyclic reducer group in both directions.

The electronic control unit of the system was programmed via Matlab $\backslash$ Simulink "C" compilation. This solution had a reduced development time and high compatibility with other existing codes (already developed for similar applications within the working group). It also enables the use of high-level libraries for future development of control capabilities, and guarantees portability of the software in case of system upgrades.

The automatic braking device was built using low-cost, onthe-shelf components, resulting in a modular system in which each part can be substituted or modified for possible needs derived from future field testing. The main electronic control unit was an Arduino UNO device (installed microcontroller: ATmega328P), which resulted satisfactory for the current needs, while future upgrades using different microcontrollers (e.g. ATmega2560, installed on Arduino MEGA devices) are possible. Such microcontrollers are compatible with CANbus devices (e.g. MCP2515 controller) to read/write signals if interfaced with vehicle on-board network. The final size of the system is compatible with the installation on the motorcycle since it can be contained on a compact tank bag (see Fig.2).

The selected motor was a PM - DC type. To obtain actuation on both directions, an H-bridge electric drive was installed; an integrated driver and Mosfet unit was in place. The final components selected for the application and its functional layout are depicted in Fig. 2 and Fig. 3.

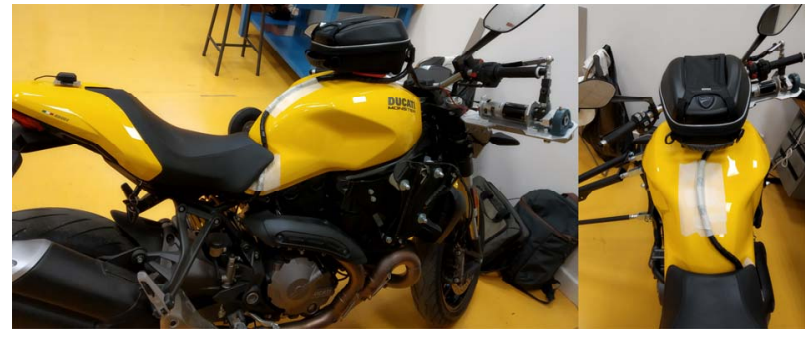

Fig. 2. Complete system installed on the vehicle.

TABLE I. COMPONENTS FOR SYSTEM CONTROL AND ACTUATION.

\begin{tabular}{|c|c|c|}
\hline Feature & Device & Component description \\
\hline $\begin{array}{l}\text { Electronic control } \\
\text { unit }\end{array}$ & Arduino UNO & $\begin{array}{l}\text { Microcontroller based on } \\
\text { ATmega328P }\end{array}$ \\
\hline Electric drive & $\begin{array}{l}\text { Full bridge motor } \\
\text { drive based on } \\
\text { VHN5019A-E }\end{array}$ & $\begin{array}{c}\text { Current up to 30A (12A } \\
\text { continuous) } \\
\text { Current control through PWM } \\
\text { signal } \\
\text { Current sensing through Analog } \\
\text { voltage signal }\end{array}$ \\
\hline Remote control & $\begin{array}{l}\text { RF remote } \\
\text { command } \\
\text { (Pushbutton - } \\
\text { relay). }\end{array}$ & $\begin{array}{c}\text { 433Mhz transmission } \\
\text { Output through STSP NO relay. } \\
150 \mathrm{~m} \text { working distance. }\end{array}$ \\
\hline Lever actuation & $\begin{array}{c}\text { DC Motor } \\
\text { 100:1 gearbox }\end{array}$ & $\begin{array}{c}\text { Nominal voltage: } 12 \mathrm{~V} \\
\text { Torque-to-current constant } \\
\text { (motor shaft): } 0.0156 \mathrm{Nm} / \mathrm{A} \\
\text { Rated torque (gearbox output } \\
\text { shaft): } 9.8 \mathrm{Nm}\end{array}$ \\
\hline
\end{tabular}

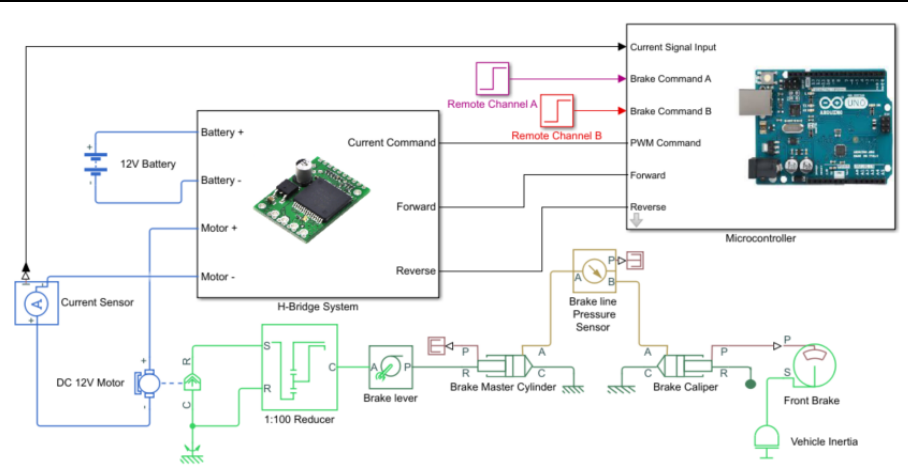

Fig. 3. Functional layout of electric system including: Microcontroller; Hbridge system; Drive and braking system. Symbols and colors are selected within standard Simulink physical libraries, lines and blocks corresponding to a different physical domain: electric devices (light blue); mechanical rotational devices (light green); mechanical translational devices (green); Hydraulics (yellow).

\section{E. Activation logic and control}

The software implemented in the microcontroller included a feedback control of the motor current. The current amplitude is proportional to the motor torque and, therefore, to the pressure generated in the braking system. The reference current is compared with the current circulating in the motor, measured by the the motor driver integrated unit; a PID system provides error compensation through the generation of a 0 to $100 \%$ 
signal, directly used to feed the H-bridge driver with a PWM control signal.

After receiving a triggering signal from the external remote control unit, the microcontroller program starts a control loop: a target current is set, the motor direction is set to 'forward', and - after controlling the motor current for a predefined period - motor rotation is reversed in order to release the system actuation on the brake lever. Two different triggers were defined. The first one (Command A in Fig.4) corresponds to a certain vehicle deceleration, the second one to a higher value (Command B). The program runs at $10 \mathrm{~ms}$ time step using an ODE1 fixed step solver.

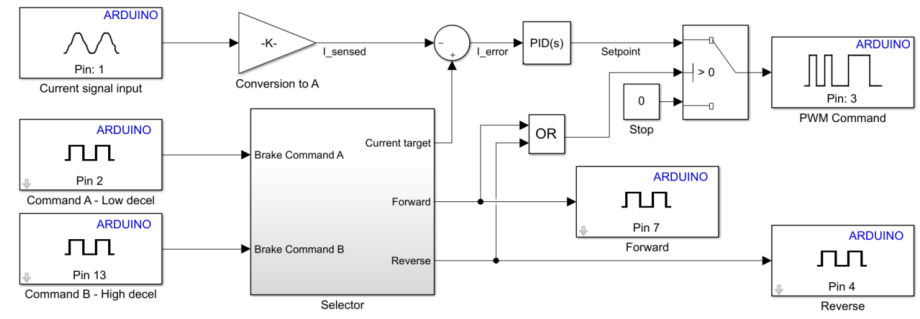

Fig. 4. Simulink program deployed as a compiled $\mathrm{C}$ code on the microcontroller.

\section{CALIBRATION AND TESTING OF THE SYSTEM.}

\section{A. Preliminary calibration}

An initial set up of the system was performed, which provided a preliminary calibration of the gain of each component based on predefined motor current values and front brake pressure targets (see Table II). Then, a few tests were performed to assess the overall system performance. As depicted in Fig. 3, the system reacted as expected, since the effective measured current in the motor was proportional to the target (expressed as a variable voltage), while the pressure output on front brake system was close to the target values; pressure outputs in a series of repetitions also satisfactory repeatability.

TABLE II. DATA FOR SYSTEM CALIBRATION AND TARGET ACHIEVEMENT

\begin{tabular}{|c|c|c|}
\hline Item & Limits & Value \\
\hline $\begin{array}{c}\text { Current command } \\
\text { (reference voltage to } \\
\text { request a certain } \\
\text { current) }\end{array}$ & Max value: 20A @5V & $4 \mathrm{~A} / \mathrm{V}$ \\
\hline $\begin{array}{c}\text { Current measured } \\
\text { (sensor output) }\end{array}$ & Min value: 0V @0A & $0.140 \mathrm{~A} / \mathrm{V}$ \\
\hline PID Gain & $\begin{array}{c}\text { Max PID output value: } \\
\text { 255 (corresponding to } \\
100 \% \text { PWM duty cycle) }\end{array}$ & $\mathrm{P}=15$ \\
$\mathrm{I}=1$ \\
$\mathrm{D}=0$
\end{tabular}

For the measured time frame, a number of samples at which the current was considered stable (i.e. $\mathrm{I} / \mathrm{dt}<2 \mathrm{~A} / \mathrm{s}$ ) were used to assess the linearity between current and pressure (see Fig. 6). The dispersion of the measured points was within the expected threshold. Such dispersion, considering the braking system, was clearly related to: (I) the time needed for the actuator to reach lever stroke (approximately 30-40 mm, a value which was not accurately measured during datalogging); (ii) the delay between brake cylinder displacement and pressure increase.
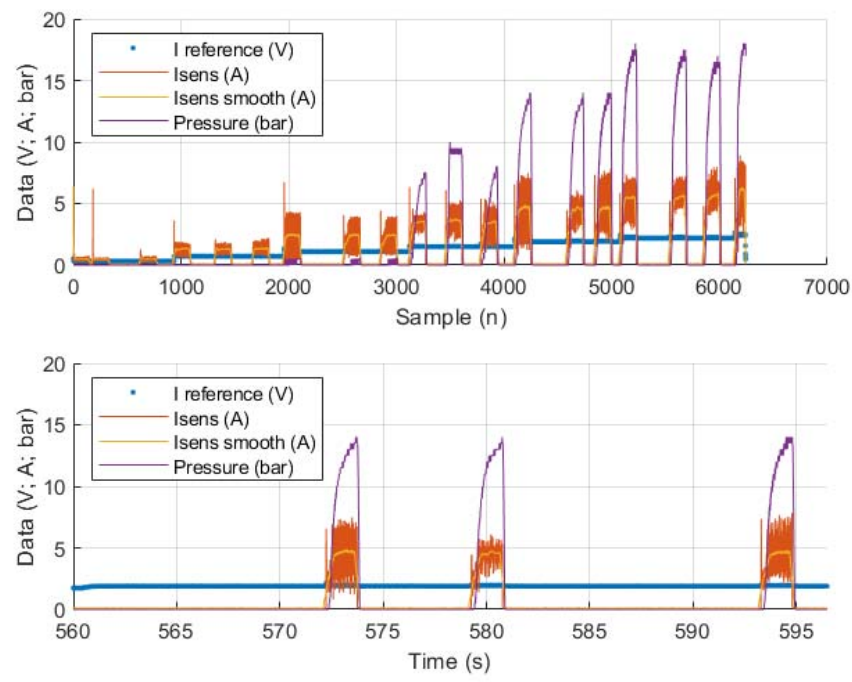

Fig. 5. Testing of the system results. I reference is a variable voltage corresponding to a current request; Isens is the output of the current sensor; for better readability, it has been smoothed using a 10 points moving average (100ms time frame); front brake pressure is also plot. Upper plot: results on various I reference values. Lower plot: focus on three repetition.

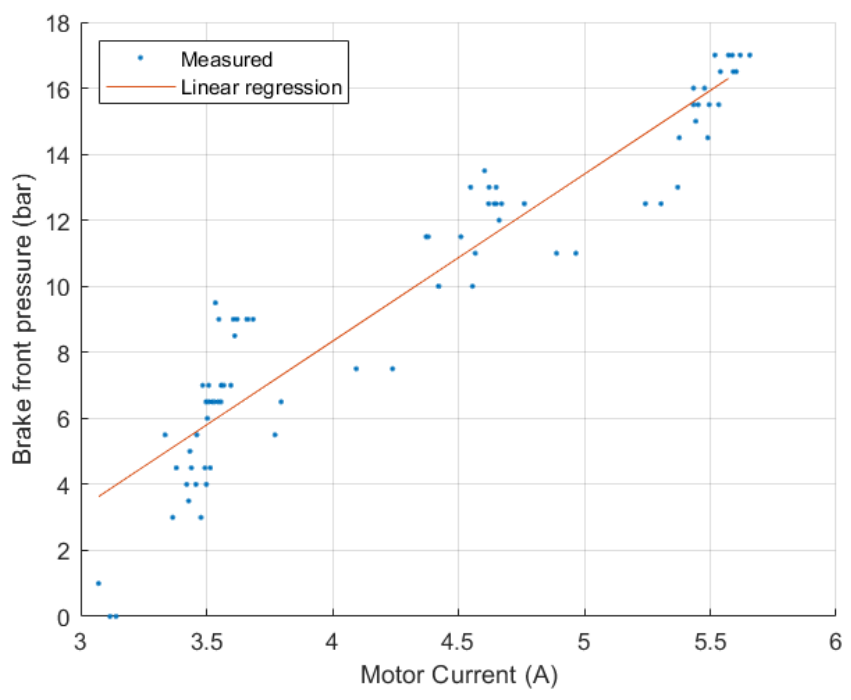

Fig. 6. Comparison with measured data and their linear regression. Rsquared is 0.885 . 


\section{B. Calibration based on vehicle testing}

The second phase of the calibration of the system aimed at reducing the time needed to achieve the target pressure and at improving the final brake lever release. This phase started with the definition of target decelerations, the corresponding target pressures and finally the related control inputs for the prototype braking system. Fig.7 shows the results of a set of tests aimed at identifying a relationship between vehicle deceleration and hydraulic pressure on the front brake circuit. The analysis of the field tests showed that even if the R-squared value was low (approx. 0.6), in practice the relationship obtained was strong enough for our use case. The possible reason for the small correlation value is that the points used for the regression included the whole transient phase of each manoeuvre. In conclusion, the target pressure for a target average deceleration of $5 \mathrm{~m} / \mathrm{s}^{2}$ was set to 12 bar.

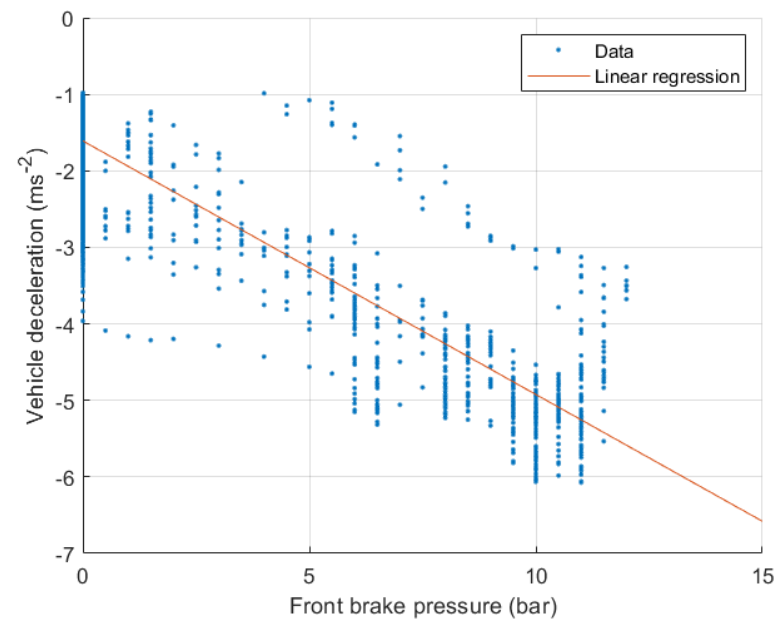

Fig. 7. Results of vehicle measurements on early testing. Relation between Front brake pressure and overall deceleration.

\section{Final calibration and results}

The tests highlighted the need to reduce the duration of the transient phase. Since a detailed model of the braking system was not available, a tabulated voltage-current value (the latter being the input to the motor current feedback system) was built on the basis of experimental data, considering the freeplay of the brake lever and the typical response of a full braking system. A high value for the initial reference current was chosen to to reduce the time needed to reach the target steady state value; this phase was called "pull-in" and its duration was initially set to $100 \mathrm{~ms}$. However, we observed that with higher reference current values, such time can be reduced significantly. After the pull-in phase, the reference current is abruptly reduced and then it follows a ramp up to a predefined value, selected on the basis of the preliminary characterization, to maintain the desired braking pressure. Following that, the reference current is reduced to produce the brake pressure release and the final reverse motion of the motor. Details of the control sequence are depicted in Fig.8.
The typical current-pressure and deceleration trends obtained with the final application of the system after calibration are depicted in in Fig. 9. Table III shows that the brake pressure obtained in subsequent tests in various riding situations was adequate for achieving the desiderd deceleration in more than $90 \%$ of the cases. Such result is satisfactory for the system under development and could be further improved by modifying the system, for example including a control feedback on the braking pressure, or directly on the vehicle deceleration.

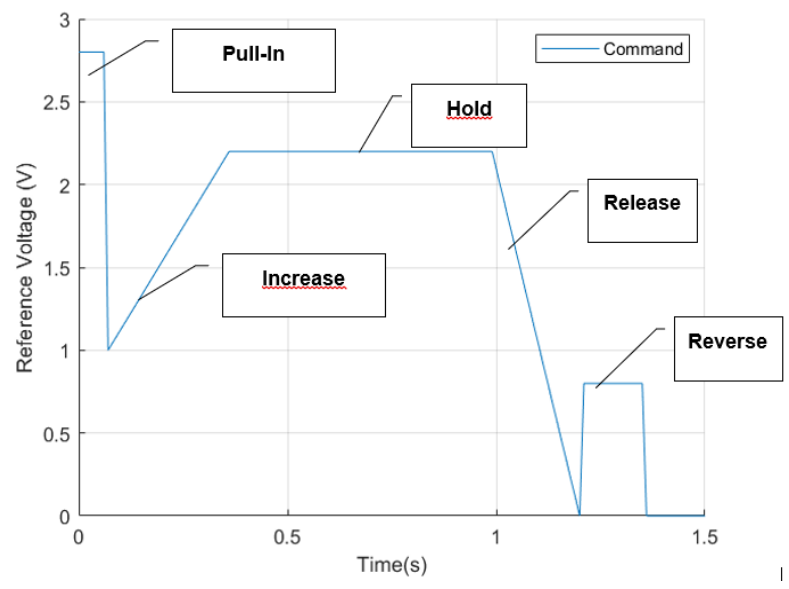

Fig. 8. Command signal built up for the application and its main phases.

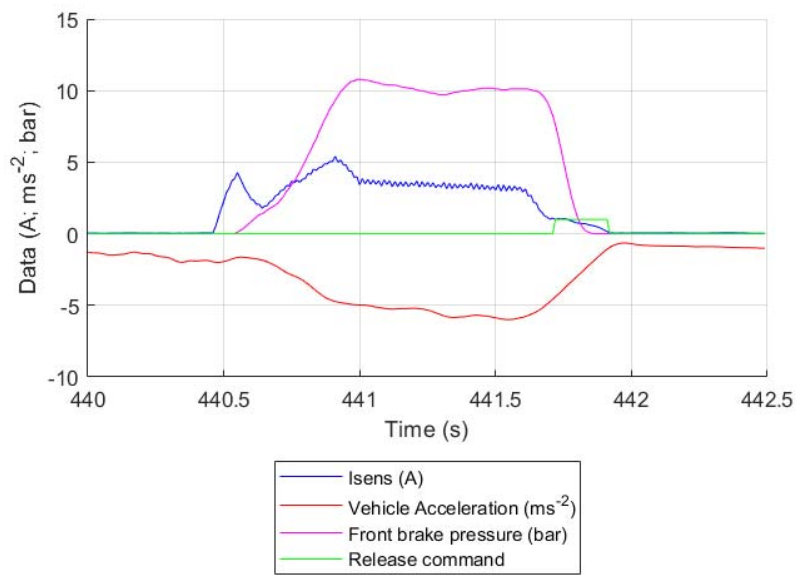

Fig. 9. Example of pressure application. Left: full data. Right: motor current and deceleration of the vehicle.

TABLE III. SUMMARY OF RESULTS AFTER EXECUTION OF ACTIVATION EVENTS WITH A RIDER IN REAL-USE CONDITIONS.

\begin{tabular}{|l|c|c|c|c|c|c|}
\hline \multicolumn{7}{|c|}{ Vehicle road test } \\
\hline $\begin{array}{l}\text { Total Straight } \\
\text { activations } \\
\text { of the } \\
\text { system }\end{array}$ & Slalom & $\begin{array}{l}\text { Lane } \\
\text { change }\end{array}$ & Curve & $\begin{array}{l}\text { Events with } \\
\text { unsufficient } \\
\text { pressure }\end{array}$ & $\begin{array}{c}\text { Critical } \\
\text { events } \\
\text { for the } \\
\text { rider }\end{array}$ \\
\hline 22 & 12 & 4 & 4 & 2 & 2 & 0 \\
\hline
\end{tabular}




\section{CONCLUSIONS}

The remote-controlled braking device presented in this paper enabled pilot tests to further develop MAEB system and to define new test protocols for the evaluation of the feasibility of automatic decelerations on PTWs. The proposed constructive solution fulfilled the testing requirements with a simple architecture based on standard components. Moreover, the placement of the braking device on the front assembly of the motorcycle allowed to embed all the components without being invasive for the rider. This solution enables many adjustments and easy fitting to other motorcycles. The construction of the device using standard components ensures a fast and easy assembly and great modularity: each part of the system can be easily replaced.

The prototype braking device was able to obtain the required performances of repeatability and accuracy for reaching the target current, pressure and vehicle decelerations; in typical interventions, peak decelerations of $-5 \mathrm{~m} / \mathrm{s}^{2}$ were achieved in 0.25 seconds from the remote triggering, with average deceleration rates not exceeding the conservative threshold of $20 \mathrm{~m} / \mathrm{s}^{3}$. In conclusion, the goals of the present activities were fully achieved. Future developments include the definition of a more "aggressive" calibration with shorter activation times, and the integration of the actuation logic in the CANbus system of the vehicle, in order to provide feedback according to the effective vehicle state.

\section{ACKNOWLEDGMENT}

The authors would like to acknowledge Ducati Foundation and Ducati Motor Hodling SPA for their contribution, and in particular Mr. Pierluigi Zampieri, by providing the test vehicle.

The authors also acknowledge Mr. Luca Zanovello for his involvment in the activity.

\section{REFERENCES}

[1] M. Ohlin, J. Strandroth, e C. Tingvall, "The combined effect of vehicle frontal design, speed reduction, autonomous emergency braking and helmet use in reducing real life bicycle injuries", Safety Science, vol. 92, pagg. 338-344, feb. 2017.

[2] E. R. Teoh, "Motorcycle crashes potentially preventable by three crash avoidance technologies on passenger vehicles", Traffic Injury Prevention, vol. 19, n. 5, pagg. 513-517, lug. 2018.

[3] G. Savino et al., "Further Development of Motorcycle Autonomous Emergency Braking (MAEB), What Can In-Depth Studies Tell Us? A Multinational Study," Traffic Inj. Prev., vol. 15, no. November, pp. S165-S172, 2014.

[4] G. Savino, J. Mackenzie, T. Allen, M. Baldock, J. Brown, and M. Fitzharris, "A robust estimation of the effects of motorcycle autonomous emergency braking (MAEB) based on in-depth crashes in Australia," Traffic Inj. Prev., vol. 17, pp. 66-72, 2016.

[5] M. Rizzi, A. Kullgren, and C. Tingvall, "Injury crash reduction of lowspeed Autonomous Emergency Braking (AEB) on passenger cars," Proc. IRCOBI Conf., pp. 656-665, 2014.

[6] B. Fildes et al., "Effectiveness of low speed autonomous emergency braking in real-world rear-end crashes," Accid. Anal. Prev., vol. 81, pp. 24-29, 2015.

[7] I. Symeonidis, G. Kavadarli, S. Erich, M. Graw, and S. Peldschus, "Analysis of the stability of PTW riders in autonomous braking scenarios," Accid. Anal. Prev., vol. 49, pp. 212-222, 2012.

[8] G. Savino, M. Pierini, and N. Baldanzini, "Decision logic of an active braking system for powered two wheelers," J. Automob. Eng., vol. 226, no. 8, pp. 1026-1036, 2012.

[9] F. Giovannini, G. Savino, M. Pierini, and N. Baldanzini, "Analysis of the minimum swerving distance for the development of a motorcycle autonomous braking system," Accid. Anal. Prev., vol. 59, no. 031360, pp. 170-184, 2013.

[10] G. Savino et al., "Exploratory field trial of motorcycle autonomous emergency braking (MAEB): Considerations on the acceptability of unexpected automatic decelerations," Traffic Inj. Prev., vol. 17, no. 8, pp. 1-12, 2016.

[11] N. Merkel, R. Pless, K. Scheid, and H. Winner, "Limits of Autonomous Emergency Brake Systems for Powered Two-Wheelers - an Expert Study," in Institute for Motorcycle Safety e.V., 2018, pp. 122-144.

[12]P. Seiniger, K. Schröter, e J. Gail, «Perspectives for motorcycle stability control systems», Accident Analysis \& Prevention, vol. 44, n. 1, pagg. $74-81$, gen. 2012 . 